\title{
Extracellular Peptidase Activity Tunes Motor Pattern Modulation
}

\author{
Debra E. Wood and Michael P. Nusbaum \\ Department of Neuroscience, University of Pennsylvania School of Medicine, Philadelphia, Pennsylvania 19104-6074
}

We are examining how extracellular peptidase activity sculpts the peptidergic actions of modulatory projection neurons on rhythmically active neuronal circuits, using the pyloric circuit in the stomatogastric ganglion (STG) of the crab Cancer borealis. Neurally released peptides can diffuse long distances to bind to their receptors. Hence, different neurons releasing the same neuropeptide into the same neuropil may reach the same receptor complement. However, extracellular peptidases can limit neuropeptide diffusion and terminate its actions.

Distinct versions of the pyloric rhythm are elicited by selective activation of different projection neurons, including those with overlapping sets of cotransmitters. Two of these projection neurons, modulatory commissural neuron 1 (MCN1) and the modulatory proctolin neuron (MPN), contain the neuropeptide proctolin plus GABA. MCN1 also contains Cancer borealis tachykinin-related peptide la (CabTRP la). CabTRP la is not fully

Neuropeptides appear to be released from nonsynaptic sites and can diffuse relatively long distances to reach their targets (Jan and Jan, 1982; Zupanc 1996; Karhunen et al., 2001). Peptidergic neurons that influence the same neural circuit and contain the same peptide transmitter could therefore have access to the same target receptors. One mechanism that limits the actions of neuropeptides is enzymatic degradation by extracellular peptidases (McKelvy and Blumberg, 1986; Coleman et al., 1994; Zappulla et al., 1999). Peptidase activity can limit the spatial influence, intensity, and duration of peptide action (Agnati et al., 1995; Saleh et al., 1996; Zappulla et al., 1999). However, little is known about how this activity influences peptidergic modulation of neural circuit activity.

To better understand this issue, we are examining the contributions of peptidase activity to peptidergic modulation of the pyloric circuit in the stomatogastric ganglion (STG) of the crab Cancer borealis. Selective activation of different modulatory projection neurons elicits different versions of the pyloric rhythm (Norris et al., 1996; Blitz et al., 1999). Two of these projection neurons are modulatory commissural neuron 1 (MCN1) and the modulatory proctolin neuron (MPN) (Nusbaum and Marder, 1989a,b; Coleman and Nusbaum, 1994). MCN1 and MPN elicit distinct pyloric rhythms, whereas only MCN1 activates the

Received Dec. 11, 2001; revised Jan. 24, 2002; accepted Feb. 14, 2002.

This work was supported by National Science Foundation Grant IBN-9808356 (M.P.N.) and National Institute of Neurological Disorders and Strokes Grant NS29436 (M.P.N.).

Correspondence should be addressed to Dr. Michael P. Nusbaum, Department of Neuroscience, University of Pennsylvania School of Medicine, 215 Stemmler Hall, Philadelphia, PA 19104-6074. E-mail: nusbaum@mail.med.upenn.edu.

D. E. Wood's present address: Department of Biology, Case Western Reserve University, Cleveland, OH 44106-7080.

Copyright (ㄷ) 2002 Society for Neuroscience $\quad 0270-6474 / 02 / 224185-11 \$ 15.00 / 0$ responsible for the distinct actions of MCN1 and MPN. Because there is aminopeptidase activity in the STG that terminates proctolin actions, we tested the hypothesis that the differences in the actions of MCN1 and MPN that are not mediated by CabTRP la result from the differential actions of aminopeptidase activity on proctolin released from these two projection neurons. We found that the pyloric circuit response to these two projection neurons becomes more similar when this aminopeptidase activity is blocked. This result supports the hypothesis that extracellular peptidase activity enables different projection neurons to use the same neuropeptide transmitter for eliciting distinct outputs from the same neuronal circuit.

Key words: aminopeptidase; peptidase inhibitor; cotransmission; neuropeptides; tachykinin; proctolin; stomatogastric nervous system; crustacea; neuromodulation; motor pattern generation

gastric mill rhythm in the STG (Blitz et al., 1999; Wood et al., 2000). Both of these projection neurons contain GABA and the peptide proctolin, whereas MCN1 also contains Cancer borealis tachykinin-related peptide Ia (CabTRP Ia) (Blitz et al., 1999).

Differences in cotransmitter complement are often considered key to enabling different neurons to elicit different responses from the same postsynaptic targets (Nusbaum et al., 2001). However, CabTRP Ia is only partly responsible for the different STG circuit responses to MPN and MCN1 (Wood et al., 2000). This result suggests that either one or both of these projection neurons have an additional cotransmitter or that proctolin and/or GABA have different actions on the STG circuits when released by each of these two neurons.

In this paper we examine the possibility that proctolin has different actions in the STG when released by MCN1 and MPN. Coleman et al. (1994) demonstrated the presence of an aminopeptidase activity in the STG that cleaves and inactivates proctolin. They also showed that the aminopeptidase inhibitor amastatin prevents proctolin cleavage and enhances the pyloric circuit response to applied proctolin. Here we show that amastatin also strengthens and prolongs the pyloric circuit response to MPN and MCN1 stimulation. This action of amastatin is proctolin-specific in that it did not alter the STG response to applied CabTRP Ia. To determine whether this aminopeptidase activity contributes to the distinct MCN1- and MPN-elicited pyloric rhythms, we coapplied amastatin and a CabTRP Ia antagonist, spantide I. Under these conditions, the pyloric circuit response to both projection neurons became more similar than when only spantide I was applied. These results indicate that aminopeptidase activity contributes to motor pattern modulation by limiting the effects of proctolin released by different projection neurons. 


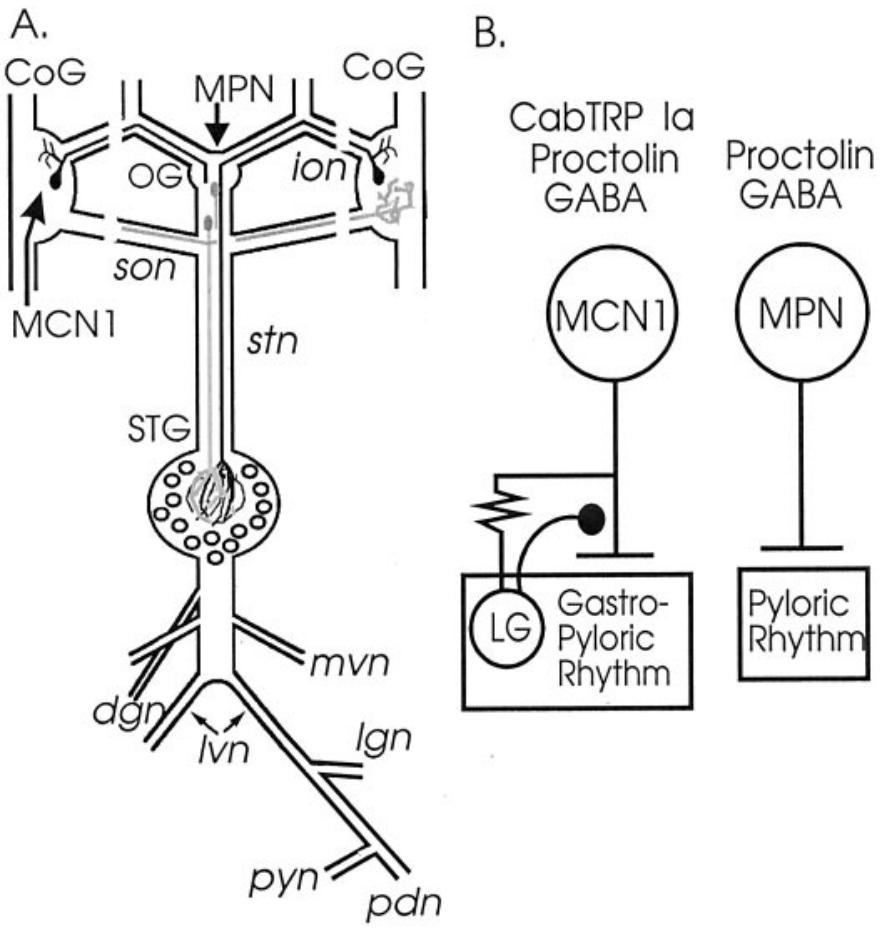

Figure 1. Schematic of the stomatogastric nervous system and the known transmitter complement of two modulatory projection neurons, MCN1 and MPN. $A$, The stomatogastric nervous system contains four ganglia, including the stomatogastric ganglion $(S T G)$, esophageal ganglion $(O G)$, and the paired commissural ganglia (CoGs), plus their connecting and peripheral nerves. The STG contains the gastric mill and pyloric circuits. Most of the modulatory projection neurons that innervate the STG originate in the OG and CoGs. MCN1 occurs as a single neuron in each $\mathrm{CoG}$, whereas MPN occurs as a pair of functionally equivalent somata in the OG. The axonal projection patterns of only one MCN1 and MPN are shown. In all experiments, the inferior (ions) and superior esophageal nerves (sons) were transected (as indicated by the broken lines) to eliminate the influence of other CoG projection neurons that innervate the STG. Anterior is toward the top. Neurons: MCN1, modulatory commissural neuron $1 ; M P N$, modulatory proctolin neuron. Nerves: dgn, dorsal gastric nerve; lgn, lateral gastric nerve; $l v n$, lateral ventricular nerve; $m g n$, medial gastric nerve; $m v n$, medial ventricular nerve; $p d n$, pyloric dilator nerve; pyn, pyloric nerve; stn, stomatogastric nerve. $B$, Schematic showing the cotransmitter complements of MCN1 and MPN, plus their actions on the STG circuits. Also illustrated are two synaptic actions that occur on the STG terminals of MCN1 and that are pivotal for enabling this neuron to elicit the gastric mill rhythm (Coleman et al., 1995; Bartos et al., 1999). T-bars represent transmitter-mediated excitation, filled circle represents synaptic inhibition, and resistor symbol represents electrical coupling.

Some of these results have appeared in abstract form (Nusbaum and Wood, 1999).

\section{MATERIALS AND METHODS}

Animals. Adult male Cancer borealis crabs were purchased from the Marine Biological Laboratory (Woods Hole, MA) and from Commercial Lobster and Seafood Company (Boston, MA). Crabs were maintained in filtered aerated artificial seawater $\left(10-12^{\circ} \mathrm{C}\right)$ until used. Before dissection, animals were anesthetized by packing them in ice for $20-40 \mathrm{~min}$. The stomach, including the stomatogastric nervous system, was removed from the animal, and the rest of the dissection was performed in chilled $\left(\sim 4^{\circ} \mathrm{C}\right)$ physiological saline. All experiments were performed on the isolated stomatogastric nervous system (Fig. 1A). Data were obtained from 35 animals.

Solutions. C. borealis physiological saline contained (mM): $\mathrm{NaCl}, 440$; $\mathrm{MgCl}_{2}, 26 ; \mathrm{CaCl}_{2}, 13 ; \mathrm{KCl}, 11$; Trisma base, 10; maleic acid, 5, $\mathrm{pH}$ 7.4-7.6. Spantide I was obtained from Peninsula Laboratories (Belmont, CA), Sigma (St. Louis, MO), or was synthesized at the Cancer Research
Center, University of Pennsylvania School of Medicine (Philadelphia, PA). CabTRP Ia was also synthesized at the University of Pennsylvania Cancer Research Center. Spantide I and CabTRP Ia solutions were prepared and applied as described previously (Christie et al., 1997; Wood et al., 2000). Spantide I was applied to the preparation for 15-20 min before stimulation of MCN1 or MPN. Proctolin and amastatin were obtained from Sigma. Solutions of amastatin or proctolin were made by diluting frozen aliquots of stock solution into C. borealis saline. Amastatin was applied for at least $10 \mathrm{~min}$ before activation of projection neurons. Preparations were washed by superfusing saline for 40-60 min before post-application controls were performed.

Electrophysiology. Electrophysiology was performed using standard methods as described previously (Bartos and Nusbaum, 1997). The stomatogastric nervous system was pinned down in a silicone elastomerlined (Sylgard 184; KR Anderson, Santa Clara, CA) Petri dish and superfused continuously $(7-12 \mathrm{ml} / \mathrm{min})$ with chilled physiological saline $\left(10-13^{\circ} \mathrm{C}\right)$. The STG and the esophageal ganglion $(\mathrm{OG})$ were desheathed to allow access for applied solutions and to facilitate intracellular recordings. The preparation was illuminated using white light transmitted through a dark-field condenser (Nikon, Tokyo, Japan). Microelectrodes (15-30 $\mathrm{M} \Omega$ ) were filled with $4 \mathrm{M}$ potassium acetate plus $20 \mathrm{~mm} \mathrm{KCl}$. Intracellular current injections were accomplished using Axoclamp 2 amplifiers in single electrode discontinuous current clamp (DCC) mode (Axon Instruments, Foster City, CA). Sample rates in DCC ranged from 2 to $3 \mathrm{kHz}$.

Identification of STG neurons was done by documenting their activity patterns, synaptic interactions, and axonal projections as described previously (Bartos and Nusbaum, 1997; Blitz and Nusbaum, 1997). Identification of the projection neurons MPN and MCN1 was made on the basis of their soma (MPN: Nusbaum and Marder, 1989a) or axon location (MCN1: Coleman and Nusbaum, 1994; Bartos and Nusbaum, 1997) and interactions in the STG (Blitz et al., 1999). Modulatory influence from projection neurons in the commissural ganglia (CoGs) onto the STG was interrupted by transecting both inferior- (ions) and superior esophageal nerves (sons) (Fig. 1A). Under these conditions the pyloric rhythm either stops or slows $(0.2-0.8 \mathrm{~Hz})$ from cycle frequencies that are typically $>1 \mathrm{~Hz}$. If it was active before transection, then the gastric mill rhythm always terminated after transection of these nerves. Selective activation of MCN1 was achieved by stimulating the ion(s) (10-20 Hz) (Coleman et al., 1995; Bartos and Nusbaum, 1997).

The pyloric cycle period was defined as the interval between the onset of an impulse burst in the pyloric dilator neuron (PD) and the onset of the subsequent PD neuron burst. Pyloric cycle frequency was determined as the reciprocal of the pyloric cycle period. Extracellular recordings were used to determine the mean number of action potentials per burst and the intraburst firing frequency for several pyloric neurons, including the lateral pyloric (LP), inferior cardiac (IC), and ventricular dilator (VD) neurons. This was possible because there is only one of each of these neurons per STG, and their action potentials can be identified unambiguously in extracellular recordings (Harris-Warrick et al., 1992). LP neuron activity was assessed from the lateral ventricular nerve (lvn), whereas IC and VD neuron activity was measured from the medial ventricular nerve $(m v n)$ (see Figs. 1A, 2A). For phase analysis, the activity of the two, functionally equivalent PD neurons was also determined. PD neuron activity was monitored from the pyloric dilator nerve $(p d n)$ (Fig. 1A). Mean values for all pyloric-related parameters were determined from measurements of 20 consecutive cycles of pyloric rhythm activity.

Activity in the lateral gastric (LG) neuron, a member of the gastric mill central pattern generator during selective activation of MCN1 (Coleman et al., 1995; Bartos et al., 1999), was monitored either extracellularly from the lateral gastric nerve (lgn) or intracellularly. In all experiments, MCN1 activity was controlled directly by the stimulation protocol, because each extracellular stimulation (duration: $1 \mathrm{msec}$ ) elicited a single action potential from MCN1. Data analysis during MPN activity came from stretches during which MPN maintained a consistent firing frequency $(15-20 \mathrm{~Hz})$ over the sample interval.

Data analysis. Data were recorded onto videotape (Wintron Technologies, Howard, PA) and chart recorder (Astro-Med MT-95000; AstroMed Inc., West Warwick, RI). Figures were prepared by scanning sequences of recordings using an HP Scanjet IIc (Hewlett Packard) with Deskscan II (version 2.0a) software. Final figures were prepared with CorelDraw (version 3.0 for Windows). Graphics and statistics were generated using Sigma Plot 4.0 and Sigma Stat 2.03 (SPSS Inc., Chicago, IL). Statistical tests used to analyze data were one-way ANOVA, re- 

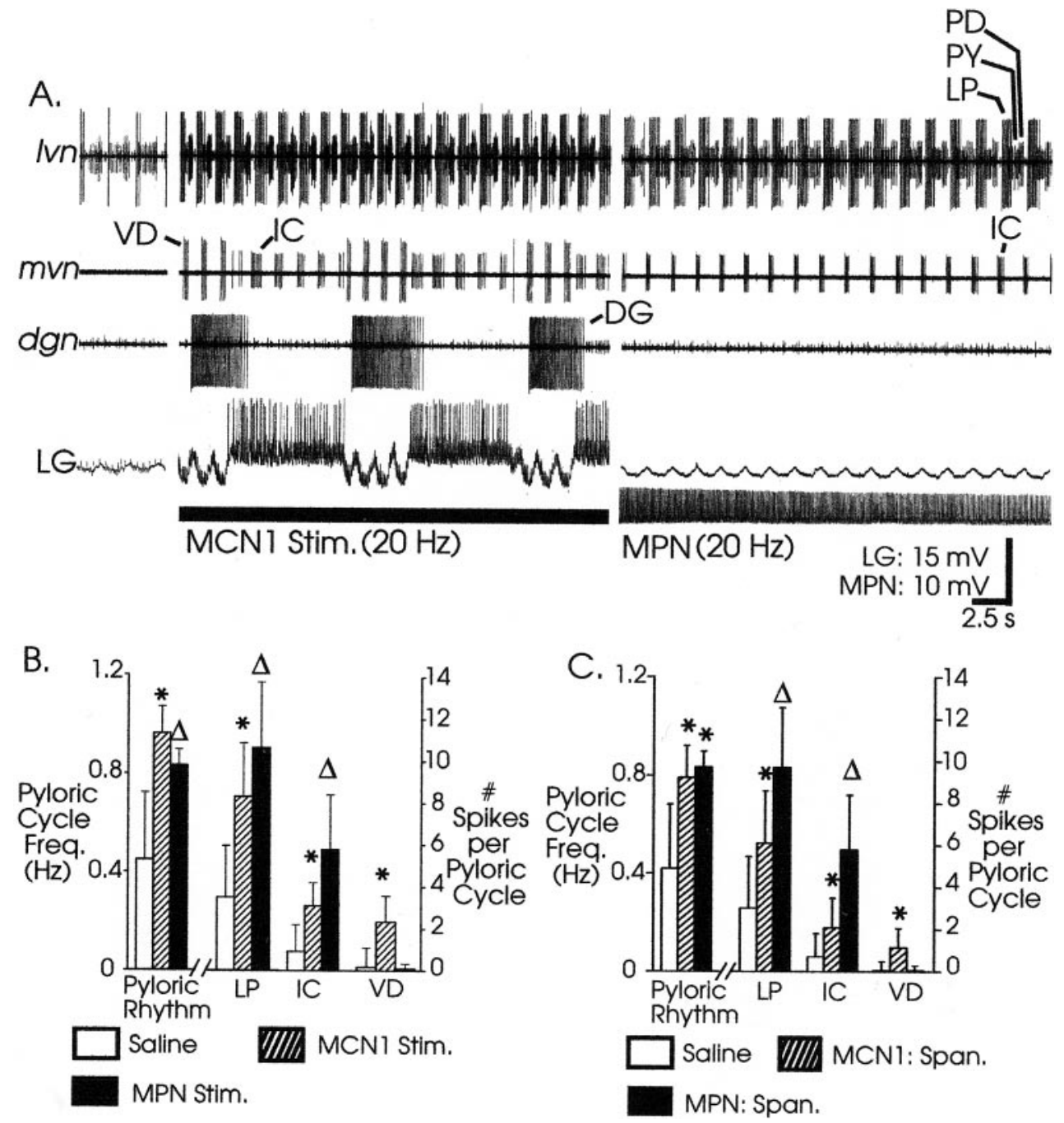

Figure 2. Tonic activation of the projection neurons MCN1 and MPN elicit distinct rhythms from the STG. $A$, Electrophysiological recordings before and during stimulation of MCN1 and MPN show that MCN1 strengthens and modifies the pyloric rhythm (lvn, $m v n)$ and activates a gastric mill rhythm $(L G, d g n)$ whereas MPN strengthens and modifies the pyloric rhythm but does not activate the gastric mill rhythm. Note that the pyloric rhythm during stimulation of these two projection neurons is distinct (e.g., $m v n$ ). Most hyperpolarized LG $V_{\mathrm{m}}$ : saline superfusion (left), $-66 \mathrm{mV}$; MCN1 stimulation, -72 $\mathrm{mV}$; MPN stimulation, $-69 \mathrm{mV}$. STG neurons: $D G$, dorsal gastric neuron; $I C$, inferior cardiac neuron; $L G$, lateral gastric neuron; $L P$, lateral pyloric neuron; $P D$, pyloric dilator neuron; $P Y$, pyloric neuron; $V D$, ventricular dilator neuron. $B$, The pyloric cycle frequency and the activity level of several pyloric neurons are enhanced by stimulation of either MCN1 or MPN, relative to ongoing pyloric rhythms during saline superfusion in the absence of stimulation. There are also differences in each of the analyzed parameters during MCN1 versus MPN stimulation. Each bar represents the mean $\pm \mathrm{SD}$ for the indicated parameter. MCN1 stimulations, $n=44$; MPN stimulations, $n=17$. *Significantly different from saline $(p \leq 0.05) ; \triangle$, significantly different from both saline alone and MCN1 stimulation $(p \leq 0.05)$. $C$, Differences persist between the pyloric rhythms elicited by MCN1 and MPN when the effects of CabTRP Ia are eliminated by spantide I (Span.) superfusion $\left(2 \times 10^{-5} \mathrm{M}\right)$. Labels same as in $B$. All three panels are from Wood et al. (2000).

peated measures ANOVA, or Friedman repeated measures ANOVA on ranks (with Tukey's test for multiple comparisons). Data are presented as means $\pm \mathrm{SD}$.

\section{RESULTS}

The MPN- and MCN1-elicited pyloric rhythms are distinct, and they remain distinct even after the actions of the MCN1 peptidecotransmitter CabTRP Ia are blocked with the tachykininreceptor antagonist spantide I (Wood et al., 2000) (Fig. 2). We therefore explored the possibility that the CabTRP Iaindependent differences in these two pyloric rhythms resulted from different actions of proctolin released from these two projection neurons. Because there is no available proctolin receptor blocker, we manipulated the level of neurally released proctolin by preventing its enzymatic degradation.

There is aminopeptidase activity that degrades and inactivates bath-applied proctolin in the STG of $C$. borealis (Coleman et al., 1994). This peptidase activity is suppressed by the aminopeptidase inhibitor amastatin, which enhances the pyloric circuit response to bath-applied proctolin (Coleman et al., 1994). For example, when amastatin $\left(10^{-5} \mathrm{M}\right)$ is applied to the STG, the pyloric rhythm response to a moderate proctolin concentration $\left(10^{-8} \mathrm{M}\right)$ is strengthened significantly such that it is indistinguishable from that seen during application of a higher $\left(10^{-7} \mathrm{M}\right)$ proctolin concentration (Coleman et al., 1994) (Fig. 3A). This result suggested that the concentration of neurally released proctolin available to receptors would also be limited by this aminopeptidase activity.

To effectively use amastatin for selectively enhancing the proctolin-mediated actions of MPN and MCN1, we first needed to determine whether amastatin also influenced the actions of CabTRP Ia, the peptide cotransmitter of MCN1 (Fig. 1B). As shown in Figure $3 B$, application of amastatin $\left(10^{-5} \mathrm{M}\right)$ did not alter the pyloric circuit response to CabTRP Ia application $\left(10^{-7}\right.$ M). For example, both the pyloric cycle frequency (CabTRP Ia: $0.75 \pm 0.08 \mathrm{~Hz}$; CabTRP Ia + amastatin: $0.78 \pm 0.10 \mathrm{~Hz})$ and the number of LP neuron spikes per cycle (CabTRP Ia: $7.1 \pm 1.5$ spikes/cycle; CabTRP Ia + amastatin: $6.8 \pm 1.9$ spikes/cycle) were the same whether or not amastatin was applied $(n=7 ; p>$ 0.05). This was not the result of a maximal action of CabTRP Ia because application of a 10-fold higher peptide concentration elicited a stronger pyloric rhythm $(n=7 ; p<0.05)$ (Fig. $3 B)$.

\section{Aminopeptidase activity influences the actions of neurally released proctolin}

It was possible that the as yet undetermined location of the aminopeptidase responsible for proctolin degradation within the STG neuropil prevented it from influencing the actions of neurally released proctolin. For example, this enzyme might be 
Figure 3. The peptidase inhibitor amastatin enhances the actions of bathapplied proctolin but not CabTRP Ia. $A$, Application of the aminopeptidase inhibitor amastatin enhanced the proctolin excitation of the pyloric rhythm. This enhancement of pyloric activity resembled that seen when a higher concentration of proctolin was applied without amastatin. Modified from Coleman et al. (1994). B, When amastatin was coapplied with CabTRP Ia there was no change in the pyloric rhythm. The lack of influence of amastatin on these CabTRP Ia actions did not result from the applied CabTRP Ia concentration eliciting a maximal pyloric response. This was supported by the fact that application of a 10 -fold higher concentration of this peptide elicited a faster and stronger pyloric rhythm.

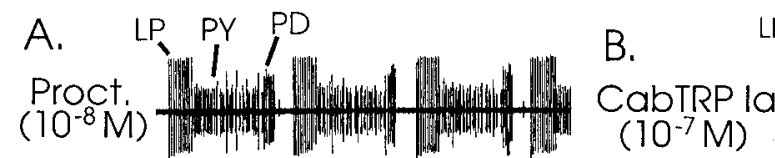

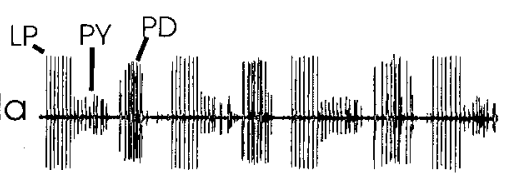

$\begin{aligned} \text { Proct. } & \text { (10-8 M)+ }\end{aligned}$

(10-8 M)+

$\left(10^{-5} \mathrm{M}\right)$

Proct.

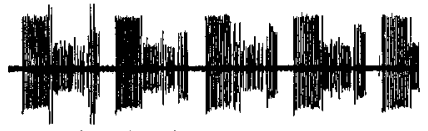

CabTRP la
$\left(10^{-7} \mathrm{M}\right)+$
Amast.
$\left(10^{-5} \mathrm{M}\right)$

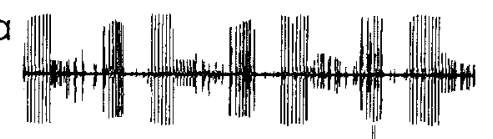

Cabtrp la
$\left(10^{-6} \mathrm{M}\right)$

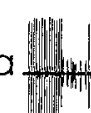

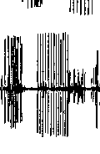

(1).

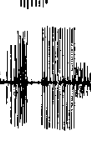

.

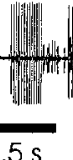



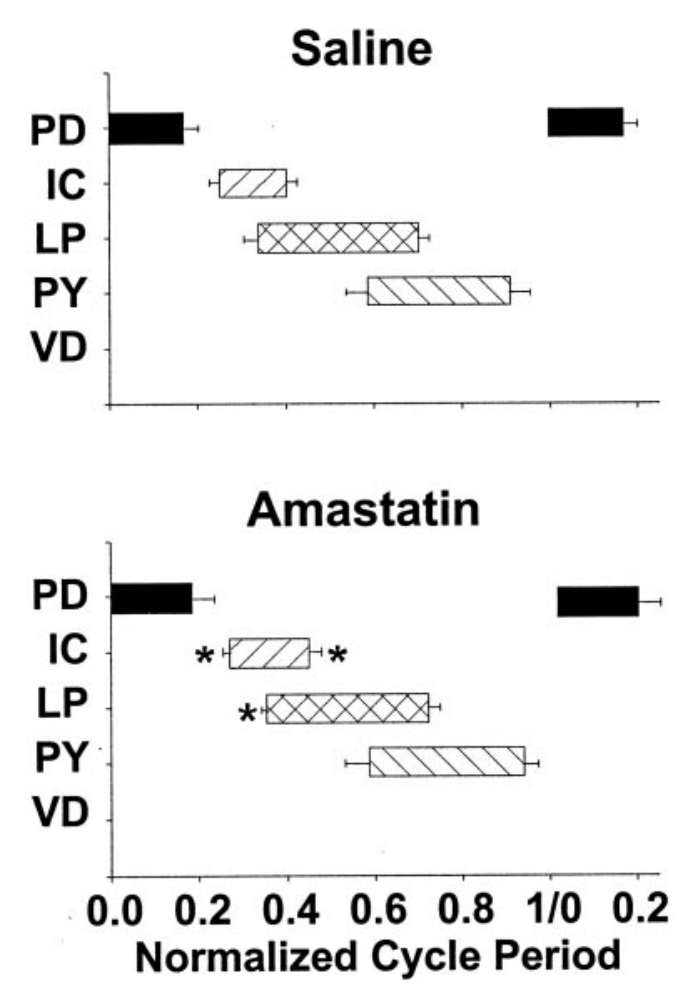

Figure 5. Suppression of aminopeptidase activity alters the pyloric motor pattern elicited by MPN stimulation. Top, The MPN-elicited pyloric motor pattern that occurred during tonic MPN stimulation $(20 \mathrm{~Hz})$ in saline is shown as a set of phase relationships (the fraction of the normalized pyloric cycle during which each neuron was active) for the pyloric motor neurons. Pyloric cycle period was arbitrarily designated as beginning with burst onset in the PD neuron and ending with the onset of the next PD neuron burst. Bottom, Pyloric motor pattern during tonic MPN stimulation $(20 \mathrm{~Hz})$ in the presence of amastatin $\left(5 \times 10^{-5} \mathrm{M}\right)$. The phase of the pyloric cycle at which burst onset and offset occurred for the PD and PY neurons was not changed by the presence of amastatin ( $p>$ $0.05 ; n=6)$. In contrast, there were changes in the phase of burst onset and offset of the IC neuron, and for the burst onset of the LP neuron $\left({ }^{*} p \leq 0.05 ; n=6\right)$. Note that the VD neuron was not active during MPN stimulation $(N=6 / 6)$. All burst onsets and offsets are presented as means $\pm \mathrm{SD}$.

results are consistent with the hypothesis that the extracellular concentration of neurally released proctolin is increased when aminopeptidase activity is blocked by amastatin.

Another function attributed to peptidase activity is that it limits the duration during which a neuropeptide can influence its targets. We therefore determined whether there was an increased duration for the MPN excitation of the pyloric rhythm. Typically, when MPN is stimulated for $\sim 10 \mathrm{sec}$ during an ongoing pyloric rhythm, its excitatory actions persist for an additional 10-20 sec after stimulation is terminated (Nusbaum and Marder, 1989b) (Fig. 6). These poststimulation effects of MPN were prolonged significantly by the presence of amastatin (control: $13.8 \pm 5.2 \mathrm{sec}$; amastatin: $52.3 \pm 21.5 \mathrm{sec} ; p<0.001 ; n=10$ ) (Fig. 6). Thus, proctolin inactivation by aminopeptidase activity does indeed limit the duration as well as the strength of the proctolinergic actions of MPN on the pyloric rhythm.

The presence of amastatin also strengthened the pyloric circuit response to MCN1 stimulation (Fig. 7), and this response was significantly prolonged compared with control stimulations (Fig. 8). As was the case with MPN stimulations, the amastatinenhanced pyloric response to MCN1 included a significant in- crease in the number of action potentials fired per pyloric cycle for the LP and IC neurons ( $p<0.05 ; n=13$ ) (Fig. $7 B$ ). Also similar to the MPN experiments was the lack of change in either the activity level of the VD neuron or in the pyloric cycle frequency when MCN1 was stimulated with amastatin present $(p>0.05 ; n=13)$ (Fig. $7 B)$.

A major goal of these experiments was to determine whether amastatin-sensitive aminopeptidase activity contributes to the generation of distinct pyloric rhythms by stimulation of MPN and MCN1. To facilitate this determination, we first characterized the MCN1-elicited pyloric rhythm during coapplication of amastatin $\left(1-5 \times 10^{-5} \mathrm{M}\right)$ and spantide I $\left(2-5 \times 10^{-5} \mathrm{M}\right)$. Spantide I blocks the actions of CabTRP Ia, the peptide cotransmitter used only by MCN1 (Fig. 1B) (Christie et al., 1997; Wood et al., 2000). As we showed previously (Wood et al., 2000), application of spantide I alone weakened the pyloric circuit response to MCN1 stimulation, although this response remained stronger than in the absence of any MCN1 activity (Figs. 2, 7). With spantide I present, there was a significant reduction in pyloric cycle frequency and in the number of action potentials per burst in the LP, IC, and VD neurons (Figs. 2, 7B). Spantide I also reduced the duration during which the pyloric rhythm remained stronger than prestimulation levels after the end of MCN1 stimulation, relative to comparable stimulations in saline $(n=11 ; p<0.05)$ (Fig. $8 B)$. This indicated that CabTRP Ia contributes to the prolonged excitation of the pyloric rhythm by MCN1. The MCN1-elicited gastric mill rhythm was also eliminated by spantide I (data not shown; Wood et al., 2000).

When MCN1 was stimulated during coapplication of spantide I and amastatin, the resulting pyloric rhythm was strengthened relative to the one elicited when spantide I alone was applied (Fig. 7). For example, there were increases in the pyloric cycle frequency and in the number of action potentials per burst in the LP, IC, and VD neurons $(n=8 ; p<0.05)$ (Fig. $7 B)$. Interestingly, the values of all four parameters were comparable to those occurring during MCN1 stimulation when amastatin alone was applied (Fig. $7 B$ ). The same result occurred with respect to the duration of enhanced pyloric rhythm activity after MCN1 stimulation. Whether spantide I and amastatin were coapplied or amastatin was applied alone, there was a comparable, significant increase in this duration relative to both saline alone and spantide I alone $(n=11 ; p<0.05)$ (Fig. 8B).

\section{Aminopeptidase activity tunes the MPN- and MCN1- elicited pyloric rhythms}

If the different pyloric rhythms elicited by MPN and MCN1 result partly from the consequences of proctolin inactivation by aminopeptidase activity, then we would expect these rhythms to become more similar when this peptidase activity is blocked. We showed previously that a number of pyloric rhythm parameters remained distinct when the MPN- and MCN1-elicited rhythms were compared during pharmacological block of the CabTRP Ia actions with spantide I (Fig. 2) (Wood et al., 2000). This includes the activity level of at least several pyloric neurons (LP, IC, and VD neurons) and many aspects of the phase relationships that define the motor pattern. Here, we compared these two rhythms during coapplication of spantide I and amastatin. Under this condition, the rhythms became more similar than when spantide I was applied by itself, although they did not become identical. Specifically, there was no longer a difference in the number of LP spikes per burst elicited during MPN and MCN1 stimulation $(n=10$; $p>0.05)$, but the number of spikes per burst in the IC and VD 


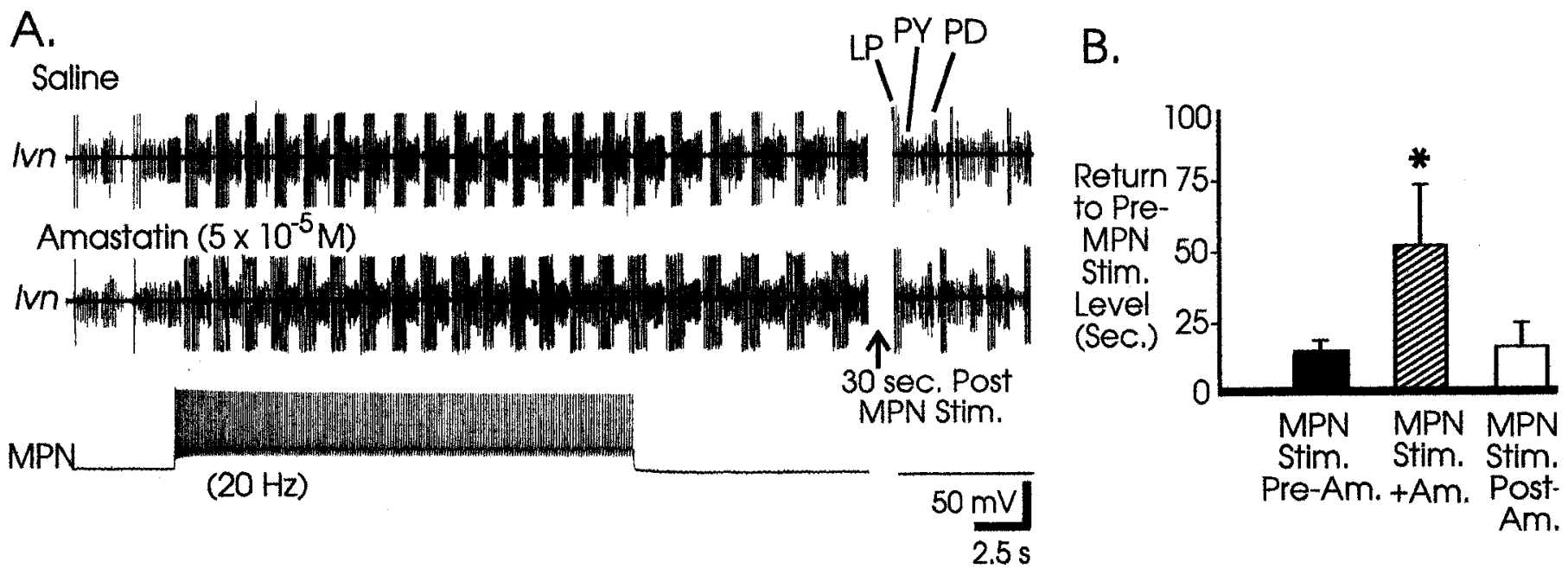

Figure 6. The continued enhancement of the pyloric rhythm after MPN stimulation is prolonged by the presence of amastatin. A, Top, By 30 sec after the end of MPN stimulation $(20 \mathrm{~Hz})$ in normal saline, the pyloric rhythm had returned to its prestimulation level of activity. Bottom, After the equivalent elapsed time post-MPN stimulation in amastatin $\left(5 \times 10^{-5} \mathrm{M}\right)$, the pyloric rhythm was still faster and stronger than the prestimulation rhythm. In both examples, MPN was stimulated for $20 \mathrm{sec} . B$, The mean duration of persistent excitation of the pyloric rhythm post-MPN stimulation was significantly increased when MPN was stimulated in the presence of amastatin. This persistent excitation was assayed via both the pyloric cycle frequency and the number of LP neuron spikes per burst. Similar differences occurred in the duration of post-stimulation pyloric rhythm activity with both of these measures. Significant difference between MPN stimulation during amastatin versus pre- and post-amastatin indicated by $*(p<0.05, n=9)$. Prestimulation $V_{\mathrm{m}}$ : MPN, $-52 \mathrm{mV}$.

neurons remained different under these two conditions $(n=10$; $p<0.001$ ) (Fig. 9). The pyloric cycle frequency was also the same when MPN and MCN1 were stimulated during coapplication of amastatin and spantide $\mathrm{I}(n=10 ; p>0.05)$ (Fig. 9), as it was when only spantide I was applied (Fig. $2 B, C$ ). With respect to pyloric neuron intraburst firing frequency during MPN and MCN1 stimulation, when spantide I and amastatin were coapplied there was no longer a difference in the PD neuron activity level (Fig. 10). LP neuron firing rate was the same during MPN and MCN1 stimulation whether spantide I was applied alone (Wood et al., 2000) or with amastatin (Fig. 10). Differences persisted in the firing rates of the IC and VD neurons. The IC neuron firing frequency was higher during MPN stimulation ( $n=7-9 ; p<$ $0.05)$, whereas the VD neuron firing frequency was higher during MCN1 stimulation $(n=7-9 ; p<0.05)$ (Fig. 10).

The actions of proctolin and CabTRP Ia converge to influence the same voltage-dependent current in nearly all pyloric neurons (Swensen and Marder, 2000, 2001). Thus, although the above comparison of MCN1 versus MPN accurately reflects the influence of enhanced proctolin levels without interference from the actions of CabTRP Ia, this comparison might overestimate the contributions of increased proctolin levels to the actions of MCN1. This might be an overestimate because the convergent actions of these coreleased peptides might normally limit, by saturation, the influence of the increased proctolin levels that occur in the presence of amastatin. The results presented in Figure 7 show that this is not the case, because the pyloric rhythm response to MCN1 stimulation was the same during amastatin alone versus amastatin plus spantide I. However, to ensure an accurate comparison of the pyloric rhythm response to stimulation of MPN and MCN1 during amastatin application, we also performed this comparison when the actions of CabTRP Ia were not blocked. The results were identical to those occurring when both amastatin and spantide I were present (Figs. 9, 10).

It was surprising that MCN1 stimulation continued to enhance LP and IC neuron activity to the same level during application of amastatin alone as during its coapplication with spantide I. This was surprising because MCN1 excitation of the pyloric rhythm is regulated by the coactivated gastric mill rhythm (Bartos and Nusbaum, 1997), and MCN1 requires the action of its peptide cotransmitter CabTRP Ia to activate the gastric mill rhythm (Wood et al., 2000). The gastric mill rhythm regulates MCN1 excitation of the pyloric rhythm via the activity of the lateral gastric (LG) neuron, which feeds back rhythmic inhibition to the STG terminals of MCN1 (Fig. 1B) (Coleman and Nusbaum, 1994). This feedback inhibition removes the MCN1 excitation of the pyloric rhythm for the duration of each LG neuron burst, including reducing the activity level of the LP and IC neurons (Bartos and Nusbaum, 1997) (M. Bartos and M. P. Nusbaum, unpublished observations). To determine the extent to which the gastric mill rhythm altered the pyloric circuit response to MCN1 stimulation during amastatin application, we compared this response with the response that occurred in the absence of LG neuron activity but with CabTRP Ia actions still present. LG neuron activity, and activation of the gastric mill rhythm, was suppressed by injecting continuous hyperpolarizing current into the LG neuron (Bartos and Nusbaum, 1997). Whether MCN1 was stimulated with the LG neuron active or inactive in the presence of amastatin, the same response occurred with respect to all parameters studied, including the mean pyloric cycle frequency and the activity level of the LP, IC, and VD neurons $(p>0.05$; $n=8$ ). For example, during amastatin superfusion the pyloric cycle frequency without MCN1 stimulation was relatively slow $(0.37 \pm 0.4 \mathrm{~Hz})$ and increased significantly $(p<0.01 ; n=8)$ and to the same extent during MCN1 stimulation with $(1.08 \pm 0.2 \mathrm{~Hz})$ and without $(0.99 \pm 0.2 \mathrm{~Hz})$ LG neuron activity suppressed. Similarly, the pre-MCN1 stimulation level of LP neuron activity was relatively low $(2.7 \pm 3$ spikes/cycle $)$, and this activity increased significantly ( $p<0.01 ; n=8)$ and equally during MCN1 stimulation with $(9.8 \pm 2$ spikes/cycle $)$ and without $(9.4 \pm 2$ spikes/cycle) LG neuron activity suppressed. The same was true for activity in the IC and VD neurons (data not shown). The 


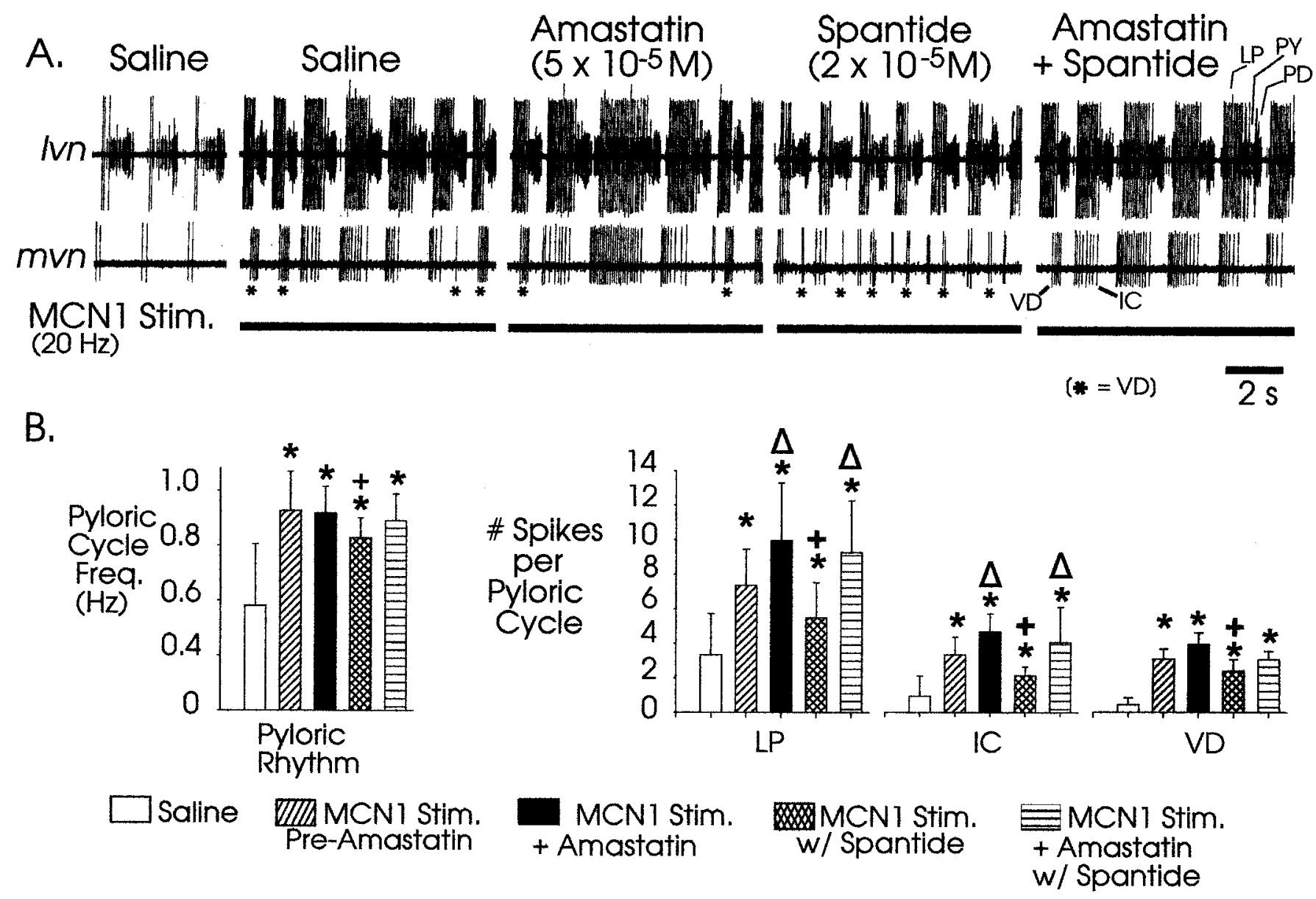

Figure 7. The aminopeptidase inhibitor amastatin enhances the pyloric circuit response to MCN1 stimulation whether or not the actions of the MCN1 cotransmitter CabTRP Ia are blocked. A, Tonic stimulation of MCN1 elicited a pyloric rhythm that was strengthened by the presence of amastatin. For example, the activity of the LP $(l v n)$ and IC ( $m v n)$ neurons were increased when amastatin was present, whether or not spantide I was coapplied. Spantide I blocks the actions of CabTRP Ia (Wood et al., 2000). A weaker pyloric circuit response occurred during comparable MCN1 stimulation in the presence of spantide I alone. B, Quantitative comparison of the pyloric circuit response to MCN1 stimulation in the abovementioned conditions. In all four conditions, MCN1 stimulation increased the pyloric cycle frequency and the number of spikes per burst in the LP, IC, and VD neurons relative to prestimulation (Saline) controls. MCN1 stimulation in the presence of spantide I alone elicited a slower pyloric cycle frequency and fewer spikes per burst in the LP, IC, and VD neurons compared with the other three MCN1 stimulation conditions. The presence of amastatin, with or without coapplied spantide I, had no influence on the pyloric cycle frequency elicited by MCN1 stimulation. However, amastatin did enhance the MCN1 excitation of the LP and IC neurons relative to MCN1 stimulation without amastatin. *, Significant difference from saline; $\triangle$, significant difference from MCN1 stimulation in saline, + , significant difference from all other conditions ( $p \leq 0.05 ; n=13)$.

ability of MCN1 to continue exciting the pyloric neurons during each LG neuron burst during amastatin application presumably resulted from the ability of amastatin to strengthen and prolong the actions of MCN1 such that they persisted throughout each LG neuron burst. A comparable situation does not occur during activation of MPN, because this projection neuron neither excites the LG neuron nor activates the gastric mill rhythm (Nusbaum and Marder, 1989b; Blitz and Nusbaum, 1997).

Wood et al. (2000) found that differences also persisted in the phase relationships that characterize the pyloric patterns elicited by MPN and MCN1 stimulation in the presence of spantide I (Fig. 11A). Many of these differences disappeared when spantide I and amastatin were coapplied (Fig. $11 B$ ). Points of convergence included the onset phase of activity in the IC, LP, and PY neurons $(p>0.05 ; n=6)$ (Fig. $11 B)$. The parameters that remained distinct when amastatin and spantide I were coapplied were the phases at which the VD neuron began and ended its burst $(p<0.05 ; n=6)$. This persisting difference in VD neuron activity resulted from the fact that this neuron was always acti- vated by MCN1, but not by MPN stimulation, under the studied conditions (Figs. 2, 4). There was also one parameter that became different during coapplication of spantide I and amastatin. This was the phase at which the IC neuron activity terminated, which occurred later in the cycle during MCN1 than during MPN stimulation (Fig. 11B).

\section{DISCUSSION}

Different modulatory neurons can elicit distinct outputs from the same neural circuit as a result of using distinct neurotransmitters or neurotransmitter complements (Blitz et al., 1999; Hurwitz et al., 1999; Wood et al., 2000; Nusbaum et al., 2001). However, as we have shown in this paper, there is also a role in this process for the same peptide transmitter having a different strength of action when released from different neurons, despite the relatively broad sphere of influence generally available to neurally released peptides (Jan and Jan, 1982; Zoli et al., 1999; Nusbaum et al., 2001). This differential effectiveness of the same neuropeptide results, at 


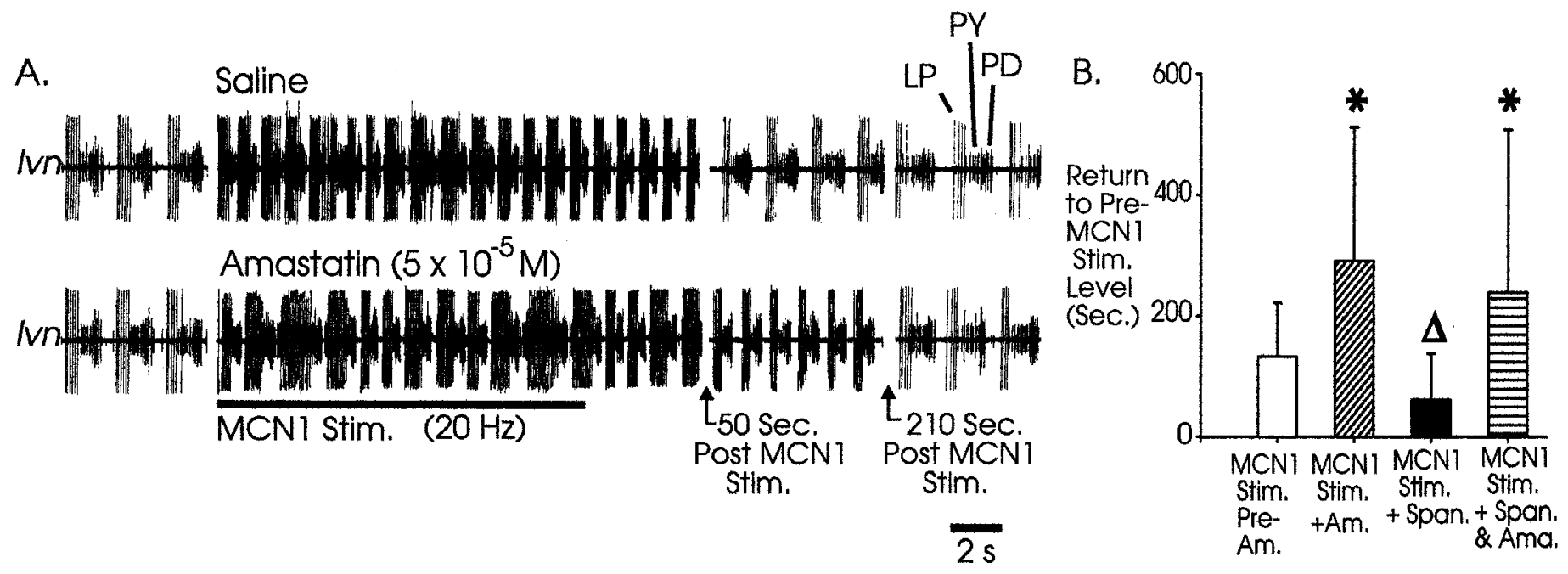

Figure 8. The continued enhancement of the pyloric rhythm after MCN1 stimulation is prolonged by the presence of amastatin. A, Top, After 50 sec had elapsed from the end of MCN1 stimulation in saline, the pyloric rhythm was nearly returned to its prestimulation level. By 210 sec post-MCN1 stimulation, the pyloric rhythm was fully returned to prestimulation levels. Bottom, After the equivalent elapsed time post-MCN1 stimulation in amastatin, the pyloric rhythm remained elevated relative to the comparable times during MCN1 stimulation in saline, and relative to its own prestimulation levels. Note that, in both examples, only the final $15 \mathrm{sec}$ of a $22 \mathrm{sec}$ MCN1 stimulation are shown. $B$, The presence of amastatin $\left(5 \times 10^{-5}\right.$ $\mathrm{M}$ ) increased the duration of the persistent excitation of the pyloric rhythm after MCN1 stimulation, whether or not the actions of CabTRP Ia were blocked with spantide I $\left(2 \times 10^{-5} \mathrm{M}\right)$. Spantide I alone reduced the duration of the persistent excitation after MCN1 stimulation. *, Significant difference from MCN1 stimulation before amastatin (or amastatin plus spantide I) application or during saline wash after these applications; $\triangle$, significant difference from MCN1 stimulation with amastatin $(p<0.05 ; n=12)$.

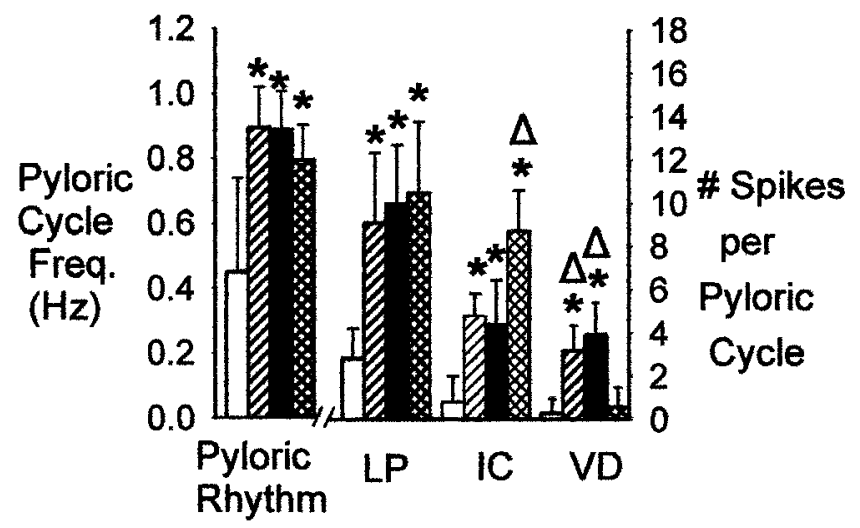

\section{Saline}

MCN MCN: w/Amastatin

MCN1: w/Spantide + Amastatin $\triangle$ MPN: w/Amastatin

Figure 9. The MCN1- and MPN-elicited pyloric rhythms become more similar when proctolin-inactivating aminopeptidase activity is blocked, whether or not CabTRP Ia actions are also blocked. There was no difference in either the pyloric cycle frequency or the number of spikes per burst in the LP neuron during MCN1 stimulation with amastatin $(5 \times$ $\left.10^{-5} \mathrm{M}\right)$ present alone or with spantide $\mathrm{I}\left(2 \times 10^{-5} \mathrm{M}\right)$ versus MPN stimulation with amastatin $(n=10 ; p>0.05)$. The activity level of the IC and VD neurons remained different during stimulation of these two projection neurons under these conditions $(n=10 ; p<0.05)$. *, Different from prestimulation levels; $\triangle$, different from saline controls and stimulation of the other projection neuron.

least partly, from the local sculpting of neuropeptide action by extracellular peptidase activity.

Extracellular peptidase activity cleaves neuroactive peptides, and it is a major mechanism for functional inactivation

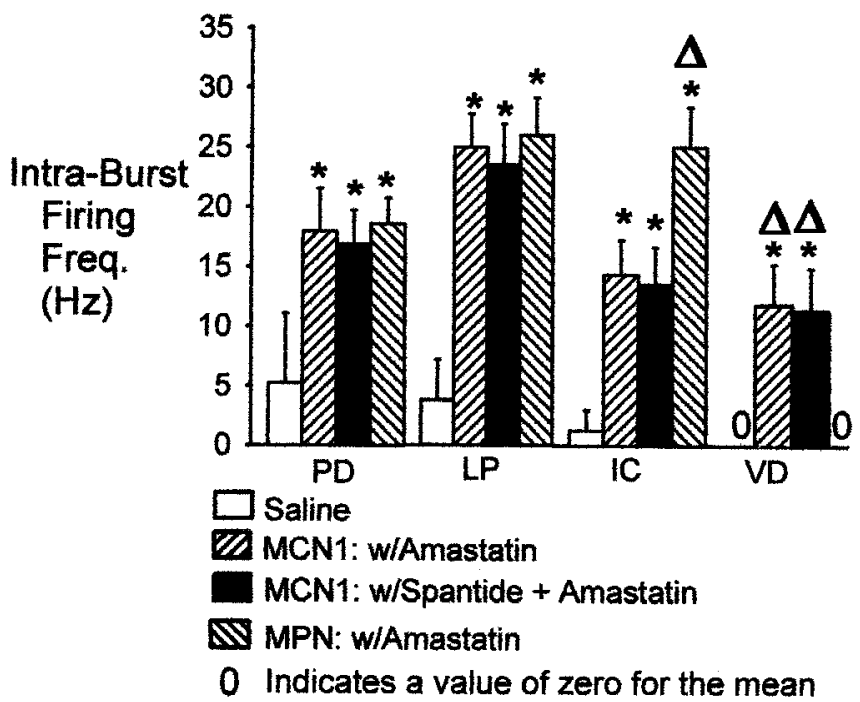

Figure 10. Convergence of intraburst firing frequency in some pyloric circuit neurons during MPN and MCN1 stimulation with proctolin actions enhanced and CabTRP Ia actions blocked. The PD, LP, and IC neurons exhibited increased firing frequency, relative to their prestimulation values, when MCN1 was stimulated with amastatin $\left(5 \times 10^{-5} \mathrm{M}\right)$ present, with or without spantide I $\left(2 \times 10^{-5} \mathrm{M}\right)$, and when MPN was stimulated with amastatin present. Under these conditions, there was no difference in PD and LP neuron firing frequency during MPN versus MCN1 stimulation, but there was a difference in the firing rate of the IC and VD neurons. IC neuron firing frequency was faster during MPN stimulation, and VD neuron firing frequency was faster during MCN1 stimulation. *, Different from prestimulation levels ( $p \leq 0.05 ; n=7) ; \triangle$, different from saline controls and stimulation of the other projection neuron $(p \leq 0.05 ; n=7)$.

of these transmitters (McKelvy and Blumberg, 1986; Duggan et al., 1992; Roques, 2000). Coleman et al. (1994) showed that aminopeptidase activity inactivates exogenous application of the peptide proctolin in the STG. They further documented 


\section{A. MCN1 w/ Spantide I}

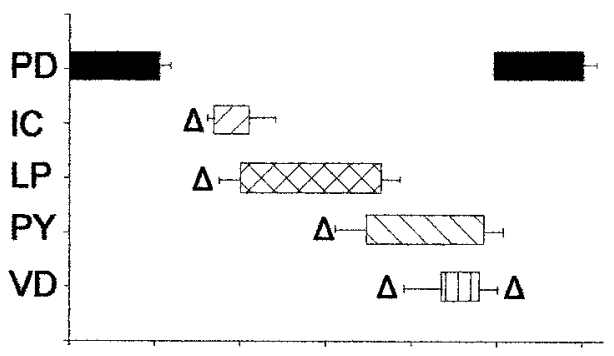

MPN

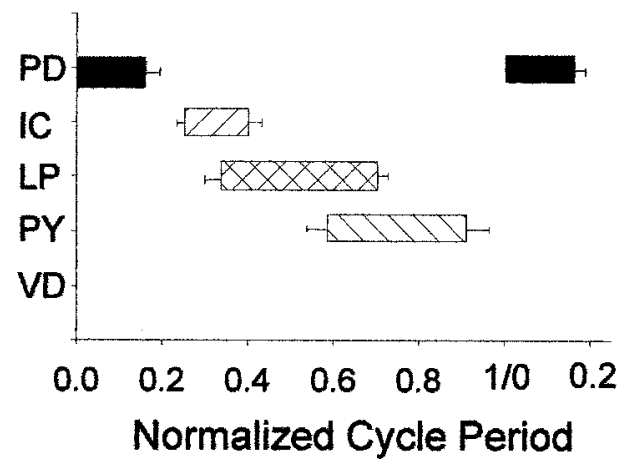

\section{B. MCN1 w/ Spantide I and Amastatin}

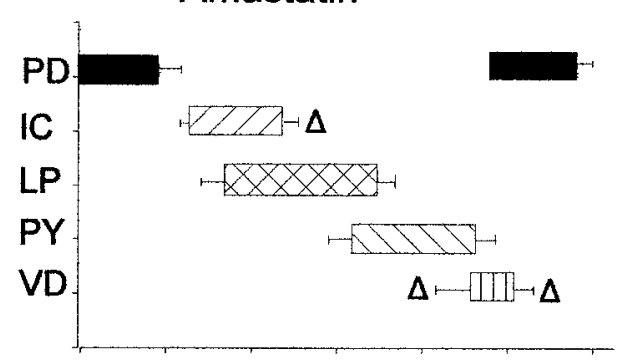

MPN w/ Amastatin

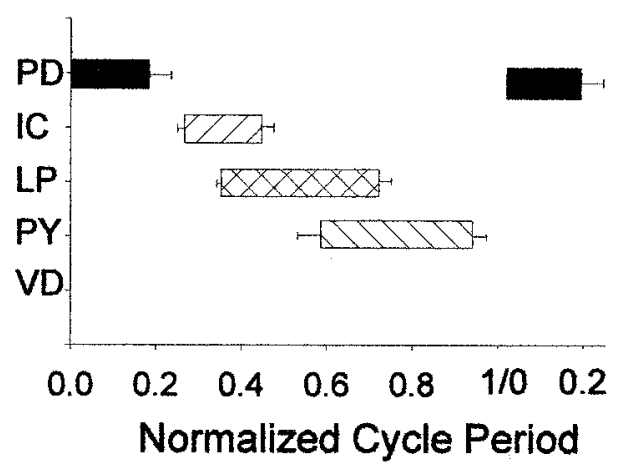

Figure 11. Peptidase activity contributes to the different pyloric motor patterns elicited by MCN1 and MPN. $A$, The pyloric motor patterns elicited by MPN and MCN1 stimulation remained distinct when CabTRP Ia actions were blocked by spantide I $\left(2 \times 10^{-5} \mathrm{M}\right)$ (from Wood et al., 2000). Each box indicates the mean fraction of the normalized pyloric cycle during which each pyloric motor neuron was active. Pyloric cycle period was arbitrarily designated as beginning with burst onset in the PD neuron and ending with the onset of the next PD burst. Note that there were differences in the onset of activity of the IC, LP, PY, and VD neurons between the MCN1- and MPN-elicited rhythms. VD activity was distinct because there was no VD activity during MPN stimulation. $\triangle$, Different from MPN stimulation $(p \leq 0.05$; $n=6) . B$, These patterns became more similar when proctolin-inactivating aminopeptidase activity was also blocked. During coapplication of spantide I $\left(2 \times 10^{-5} \mathrm{M}\right)$ and amastatin $\left(5 \times 10^{-5} \mathrm{M}\right)$, the differences in the phase of burst onset for the IC, LP, and $\mathrm{PY}$ neurons converged during the MCN1- and MPN-elicited pyloric motor patterns. Differences remained in the phase of VD neuron activity, and a new difference appeared in the phase of IC neuron burst termination. $\triangle, p \leq 0.05 ; n=6$. that this inactivation could be prevented by the aminopeptidase inhibitor amastatin. This result was extended in the present study by showing that amastatin strengthens and prolongs the actions of the two proctolinergic projection neurons, MPN and MCN1.

Functional inactivation of neuropeptide action is not the only possible outcome of peptidase activity, because in some cases this activity instead activates or alters the activity of the cleaved peptide (Réaux et al., 1999; Roques, 2000). There was no evidence in the bath-application studies for an altered function of cleaved proctolin within the STG (Coleman et al., 1994). Similarly, the presence of amastatin did not cause any qualitative changes in the pyloric response to either projection neuron, such as the excitation of a previously unaffected neuron. Moreover, all of the pyloric rhythm parameters that were changed by the presence of amastatin were the same for stimulation of MCN1 and MPN. For example, in both cases there was no change in the pyloric cycle frequency or the activity level of the VD neuron, but there was a significant increase in the activity of the LP and IC neurons. It is also worth noting that the presence of amastatin without activation of either MCN1 or MPN did not alter the pyloric rhythm, indicating that there was little if any spontaneous release of proctolin in the STG.

Thus far, studies aimed at understanding the functional consequences of neuropeptide inactivation have focused primarily on changes in the responsiveness of individual target neurons (Sigvardt et al., 1986; Owens et al., 1992; Rose et al., 1996; Saleh et al., 1996; Chen and Pittman, 1997; Kombian et al., 1997). Here we extend the results of these previous studies by showing that aminopeptidase activity contributes to motor pattern modulation by limiting the actions of neurally released proctolin. This enables a different response magnitude in the same target neurons to the proctolinergic actions of the projection neurons MCN1 and MPN, thereby contributing to the different pyloric rhythms elic- ited by these projection neurons in the crab stomatogastric system.

The lack of change in the pyloric cycle frequency during stimulation of either MCN1 or MPN with amastatin present might seem at odds with previous studies that showed proctolin having a dose-dependent action on the speed of this rhythm (Marder et al., 1986; Nusbaum and Marder, 1989b). However, previous work also showed that the action of both applied and neurally released proctolin on the pyloric cycle frequency is state-dependent such that proctolin elicits a maximal pyloric cycle frequency that is already attained by MPN stimulation without amastatin present and by MCN1 stimulation with spantide I present (Hooper and Marder, 1987; Nusbaum and Marder, 1989b; Wood et al., 2000).

Despite the different pyloric rhythms elicited by MCN1 and MPN, there is a strong convergence of action of proctolin and CabTRP Ia on the pyloric circuit in C. borealis. This is because, despite their acting through different receptors (Christie et al., 1997; Wood et al., 2000), these two peptides influence the same voltage-dependent current in nearly all pyloric circuit neurons (Swensen and Marder, 2000, 2001). This convergence at the level of the affected ionic current provides the possibility that the normal amounts of co-released CabTRP Ia and proctolin might maximally activate the affected current. This, however, was not the case because amastatin strengthened the LP and IC neuron responses to MCN1 activity even when CabTRP Ia actions were not blocked. Our results also provide support for the convergence of these peptide cotransmitter actions at the circuit level, because the pyloric circuit response to MCN1 was the same whether amastatin was applied alone or coapplied with the tachykininreceptor blocker spantide I. Both of these conditions were more effective than when spantide I alone was present during MCN1 stimulation. 
Given this strong degree of convergence with respect to the targets and actions of proctolin and CabTRP Ia, it may seem surprising that MCN1 and MPN do elicit different pyloric rhythms. However, these two neurons appear likely to influence at least some of their pyloric target neurons via different, and submaximal local proctolin concentrations, and different concentrations of applied proctolin do elicit distinct versions of the pyloric rhythm (Marder et al., 1986). The submaximal actions of the combination of proctolin and CabTRP Ia released by MCN1 might also result from the fact that access of CabTRP Ia for its receptors is also locally regulated in the STG by extracellular peptidase activity (Wood et al., 2000). There may also be different amounts of proctolin released per action potential by MPN and MCN1. Such a situation has been documented in the Aplysia neuromuscular system, where different identified neurons release different amounts of the same neuropeptide when active at the same firing frequency (Vilim et al., 2000).

The differences in the pyloric rhythms elicited by MPN and MCN1 may well also result partly from these two projection neurons having distinct GABAergic synapses on the pyloric neurons. For example, the ability of MCN1 but not MPN to enhance the activity of the VD neuron, even with CabTRP Ia actions blocked, might result from such a synapse. However, it is not yet known whether MCN1 action potentials elicit unitary synaptic potentials in the VD neuron. Furthermore, although focally applied GABA does have both excitatory and inhibitory actions on STG neurons, and all pyloric neurons respond to GABA application, the discrete GABAergic actions of MCN1 and MPN on pyloric neurons have yet to be elucidated because available antagonists do not effectively block all GABA actions in the STG (Swensen et al., 2000). There is also the possibility that one or both of these projection neurons has at least one additional neurotransmitter, although there are at least six neuromodulators that localize to STG input neurons that are not found in either of these neurons (Blitz et al., 1999). If there are additional transmitters mediating the remaining differences in the pyloric rhythms elicited by MCN1 and MPN, they most likely occur in MCN1 because both MPN stimulation and proctolin application elicit the same pyloric rhythm (Nusbaum and Marder, 1989b).

In conclusion, the present results support the hypothesis that having a distinct cotransmitter complement is not necessary for enabling different projection neurons to elicit distinct motor patterns from the same neuronal circuit. By locally controlling the access of a neuropeptide to its receptors, extracellularly located peptidase activity can enable different modulatory neurons to use the same neuropeptide to elicit distinct levels of activity and burst relationships from the same set of neurons within a multifunctional neuronal network. Overall, however, it is likely that the ability of different projection neurons to evoke distinct motor patterns from any one neuronal network results from the use of a combination of distinct mechanisms.

\section{REFERENCES}

Agnati LF, Zoli M, Stromberg I, Fuxe K (1995) Intercellular communication in the brain: wiring versus volume transmission. Neuroscience 69:711-726.

Bartos M, Nusbaum MP (1997) Intercircuit control of motor pattern modulation by presynaptic inhibition. J Neurosci 17:2247-2256.

Bartos M, Manor Y, Nadim F, Marder E, Nusbaum MP (1999) Coordination of fast and slow rhythmic neuronal circuits. J Neurosci 19:6650-6660.
Blitz DM, Nusbaum MP (1997) Motor pattern selection via inhibition of parallel pathways. J Neurosci 17:4965-4975.

Blitz DM, Christie AE, Coleman MJ, Norris BJ, Marder E, Nusbaum MP (1999) Different proctolin neurons elicit distinct motor patterns from a multifunctional neuronal network. J Neurosci 19:5449-5463.

Chen X, Pittman QJ (1997) Vasopressin and amastatin induce $\mathrm{V}_{1^{-}}$ receptor-mediated suppression of excitatory transmission in the rat parabrachial nucleus. J Neurophysiol 82:1689-1696.

Christie AE, Lundquist CT, Nässel DR, Nusbaum MP (1997) Two novel tachykinin-related peptides from the nervous system of the crab Cancer borealis. J Exp Biol 200:2279-2294.

Coleman MJ, Nusbaum MP (1994) Functional consequences of compartmentalization of synaptic input. J Neurosci 14:6544-6552.

Coleman MJ, Konstant PH, Rothman BS, Nusbaum MP (1994) Neuropeptide degradation produces functional inactivation in the crustacean nervous system. J Neurosci 14:6205-6216.

Coleman MJ, Meyrand P, Nusbaum MP (1995) A switch between two modes of synaptic transmission mediated by presynaptic inhibition. Nature 378:502-505.

Duggan AW, Schaible HG, Hope PJ, Lang CW (1992) Effect of peptidase inhibition on the pattern of intraspinally released immunoreactive substance $P$ detected with antibody microprobes. Brain Res 579:261-269.

Golowasch J, Marder E (1992) Proctolin activates an inward current whose voltage dependence is modified by extracellular $\mathrm{Ca}^{2+}$. $\mathrm{J}$ Neurosci 12:810-817.

Harris-Warrick RM, Marder E, Selverston A, Moulins M (1992) Dynamic biological networks: the stomatogastric nervous system. Cambridge, MA: MIT

Hooper SL, Marder E (1987) Modulation of the lobster pyloric rhythm by the peptide proctolin. J Neurosci 7:2097-2112.

Hurwitz I, Perrins R, Xin Y, Weiss KR, Kupfermann I (1999) C-PR neuron of Aplysia has differential effects on "feeding" cerebral interneurons, including myomodulin-positive CBI-12. J Neurophysiol 81:521-534.

Jan LY, Jan YN (1982) Peptidergic transmission in sympathetic ganglia of the frog. J Physiol (Lond) 327:219-246.

Karhunen T, Vilim FS, Alexeeva V, Weiss KR, Church PJ (2001) Targeting of peptidergic vesicles in cotransmitting terminals. J Neurosci 21:RC127(1-5).

Kombian SB, Mouginot D, Pittman Q (1997) Dendritically released peptides act as retrograde modulators of afferent excitation in the supraoptic nucleus in vitro. Neuron 19:903-912.

Marder E, Hooper SL, Siwicki KK (1986) Modulatory action and distribution of the neuropeptide proctolin in the crustacean stomatogastric nervous system. J Comp Neurol 243:454-467.

McKelvy J, Blumberg S (1986) Inactivation and metabolism of neuropeptides. Annu Rev Neurosci 9:211-248.

Norris BJ, Coleman MJ, Nusbaum MP (1996) Pyloric motor pattern modification by a newly identified projection neuron in the crab stomatogastric nervous system. J Neurophysiol 75:97-108.

Nusbaum MP, Marder E (1989a) A modulatory proctolin-containing neuron (MPN). I. Identification and characterization. J Neurosci 9:1591-1599.

Nusbaum MP, Marder E (1989b) A modulatory proctolin-containing neuron (MPN). II. State-dependent modulation of rhythmic motor activity. J Neurosci 9:1600-1607.

Nusbaum MP, Wood DE (1999) The role of cotransmitters and peptidase activity in shaping the actions of peptidergic neurons. Soc Neurosci Abstr 25:1967.

Nusbaum MP, Blitz DM, Swensen AM, Wood D, Marder E (2001) The roles of co-transmission in neural network modulation. Trends Neurosci $24: 146-154$

Owens DF, Menon JG, Rothman BS (1992) Structure-activity relationship of the neurotransmitter alpha-bag cell peptide on Aplysia LUQ neurons: implications regarding its inactivation in the extracellular space. J Neurobiol 23:656-670.

Réaux A, Fournie-Zaluski MC, David C, Zini S, Roques BP, Corvol P, Llorens-Cortes C (1999) Aminopeptidase A inhibitors as potential central antihypertensive agents. Proc Natl Acad Sci USA 96:13415-13420.

Roques BP (2000) Novel approaches to targeting neuropeptide systems. Trends Pharmacol Sci 21:475-483.

Rose C, Vargas F, Facchinetti P, Bourgeat P, Bambal RB, Bishop PB, Chan SMT, Moore ANJ, Ganellin CR, Schwartz J-C (1996) Characterization and inhibition of a cholecystokinin-inactivating serine peptidase. Nature 380:403-411.

Saleh TM, Kombian SB, Zidichouski JA, Pittman QJ (1996) Peptidergic modulation of synaptic transmission in the parabrachial nucleus in vitro: importance of degradative enzymes in regulating synaptic efficacy. J Neurosci 16:6046-6055.

Sigvardt KA, Rothman BS, Brown RO, Mayeri E (1986) The bag cells of Aplysia as a multitransmitter system: identification of alpha bag cell peptide as a second neurotransmitter. J Neurosci 6:803-813.

Swensen AM, Marder E (2000) Multiple peptides converge to activate 
the same voltage-dependent current in a central pattern generating circuit. J Neurosci 20:6752-6759.

Swensen AM, Marder E (2001) Modulators with convergent cellular actions elicit distinct circuit outputs. J Neurosci 21:4050-4058.

Swensen AM, Golowasch J, Christie AE, Coleman MJ, Nusbaum MP, Marder E (2000) GABA and GABA responses in the stomatogastric ganglion of the crab Cancer borealis. J Exp Biol 203:2075-2092.

Vilim FS, Cropper EC, Price DA, Kupfermann I, Weiss KR (2000) Peptide cotransmitter release from motorneuron B16 in Aplysia californica: costorage, corelease, and functional implications. J Neurosci 20:2036-2042.

Wood DE, Stein W, Nusbaum MP (2000) Projection neurons with shared cotransmitters elicit different motor patterns from the same neural circuit. J Neurosci 20:8943-8953.

Zappulla JP, Wickham L, Bawab W, Yang X-F, Storozhuk MV, Castellucci VF, DesGroseillers L (1999) Cloning and characterization of Aplysia neutral endopeptidase, a metallo-endopeptidase involved in the extracellular metabolism of neuropeptides in Aplysia californica. J Neurosci 19:4280-4292.

Zoli M, Jannson A, Sykova E, Agnati LF, Fuxe K (1999) Volume transmission in the CNS and its relevance for neuropsychopharmacology. Trends Pharmacol Sci 20:142-150.

Zupanc GKH (1996) Peptidergic transmission: from morphological correlates to functional implications. Micron 27:35-91. 